\title{
Assessing internal exposure in the absence of an appropriate model: two cases involving an incidental inhalation of transuranic elements*
}

\author{
N. BLANCHIN ${ }^{1}$, P. BÉRARD ${ }^{2}$, E. BLANCHARDON ${ }^{3}$, R. FOTTORINO $^{4}$,

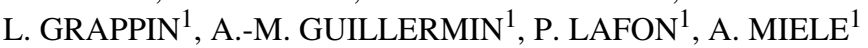

(Received 11 February 2008, accepted 23 April 2008)

\begin{abstract}
Two incidents involving internal exposure by inhalation of transuranic compounds are presented herein. The results of the measurements of urinary and faecal excretions of the two individuals involved do not concur with the values predicted by the ICRP models that should be applied by default, according to the circumstances of the incidents and the chemical form of the products involved: oxide in the first case and nitrate in the second. These cases are remarkable in the similarity of their biokinetic behaviour even though they occurred in different situations and involved different chemical compounds. Both situations provide an illustration of the management of internal contamination events. The precautions to be taken and the questions that the physician should ask himself in the estimation of the internal dose are listed as follows: What type of examinations should be prescribed and at what frequency? What analysis results should be used in assessing the dose? How can the effect of the Ca-DTPA treatment be assessed? How long is it necessary to perform radiotoxicological exams before assessing the dose? What should be done if the ICRP model corresponding to the initial circumstances does not fit the measurement data? Finally, our selected hypotheses, used to explain specific biokinetic behaviour and to estimate its intake in both cases, are detailed. These incidental contaminations suggest that further studies should be carried out to develop a new model for inhalation of transuranic compounds that would follow neither the $S$ nor the $M$ absorption type of the respiratory tract model of ICRP publication 66.
\end{abstract}

Keywords: ICRP model / transuranic elements / internal dose assessment / biokinetics

RÉSUMÉ Comment estimer une dose interne en l'absence de modèle approprié : à propos de deux cas d'inhalation incidentelle de transuranien.

Deux incidents de contamination interne par inhalation de transuraniens sont présentés ici. Dans les deux cas les résultats des mesures d'excrétion urinaire et fécales ne correspondent pas avec les valeurs attendues des modèles de la CIPR correspondant aux circonstances et aux formes chimiques présumées du produit : oxyde dans le premier cas et nitrate dans le second. Ces deux cas sont remarquables

\footnotetext{
French version of this article is available online at www.radioprotection.org.

CEA Cadarache, SST, Bâtiment 102, 13108 Saint-Paul-Lez-Durance, France.

CEA Saclay, LABM, Bâtiment 601, 91191 Gif-sur-Yvette Cedex, France.

IRSN, DRPH, Bâtiment 02, 92262 Fontenay-aux-Roses Cedex, France.

CEA Cadarache, LABM, Bâtiment 102, 13108 Saint-Paul-Lez-Durance, France.
} 


\begin{abstract}
par la similitude de leur comportement biocinétique même s'ils sont survenus dans des situations différentes avec des produits chimiques distincts. Ces deux situations illustrent la démarche d'estimation de la dose interne ainsi que les précautions devant être prises, le médecin du travail dont la mission réglementaire est l'estimation de la dose interne devra notamment se poser les questions suivantes : Quel type d'examens prescrire et à quelle fréquence ? Quels résultats d'examens utiliser pour le calcul de dose ? Comment évaluer l'effet du traitement par le CaDTPA ? Combien de temps poursuivre les examens avant d'arrêter la dose ? Que faire lorsque le modèle de la CIPR correspondant aux circonstances initiales est en discordance avec les résultats de mesure radiotoxicologique? Les hypothèses retenues pour expliquer le comportement bio-cinétique spécifique et estimer l'incorporation dans ces deux cas sont développées. Ces contaminations incidentelles suggèrent que des études doivent être menées pour développer un nouveau modèle d'inhalation pour les composés trans-uraniens ne correspondant ni au type $S$ ni au type $M$ de la publication 66 de la CIPR.
\end{abstract}

\title{
1. Introduction
}

We present here two cases of internal exposure through inhalation of transuranic elements that occurred in different circumstances illustrating the difficulties involved in dose assessment.

In standard situations, the occupational health physician in charge of the follow-up of contamination events must adopt a procedure that, among the various possibilities, does not exclude any hypothesis. He will proceed stage-by-stage examining successively:

1. the initial conditions of exposure in order to select an appropriate biokinetic model and the physico-chemical parameters,

2. the representativity of the different radiotoxicological examinations and comparison of their respective meaning,

3. the criteria for initiating and stopping a chelating treatment,

4. the results of the control measurements after the event allowing to validate the chosen hypotheses and to determine the effectiveness of the treatment,

5. the consistency between the different individual measurement results and the available models.

These two cases, which reveal considerable similarities in their retention and elimination kinetics, do not follow the curves of the International Commission on Radiological Protection (ICRP, 1997) that normally should correspond to the circumstances of the events. Due to this fact, they underline the problem encountered by field practicians in the application of the reference models (Appendix in the Decree of 01/09/03 and the ISO norm 20553 of July 2006) and the necessity of resorting to alternative methods to estimate the intake properly. 


\section{First case}

\subsection{Circumstances of the event}

Mr. TP, a production operator was transferring plutonium oxide pots that had been stored for many years at the storage facility for their reconditioning. He was working in a cotton uniform with no respiratory protective equipment. While removing a pot from a storage compartment, he noticed that the double vinyl envelope was deteriorated. He placed the pot in a transfer cage and continued his work. About one to two minutes later, an atmospheric contamination of 100 DAC (Derived Air Concentration) and 27 DAC.h was detected by the air monitoring equipment (EDGAR) placed at approximately 3 meters from the operator. This person was immediately evacuated from the cell.

The Radiation Protection Department revealed a surface contamination of $15 \mathrm{~Bq}$ on the right hand. Such contamination will disappear with no problem after an initial washing. There is no further trace of external contamination. The sample taken from the nasal mucus is measured at $3.2 \mathrm{~Bq}$, an activity confirmed by blowing the nose, the activity of which is measured at $1.9 \mathrm{~Bq}$ of alpha activity.

In conformance with the established protocol of the CEA Occupational Medicine Department in Cadarache (Blanchin et al., 2004) an intravenous injection of half an ampulla of tricalcic diethylene triamine penta-acetic acid (Ca-DTPA, $500 \mathrm{mg}$ ) was administered after the occurrence of the incident. Mr. TP was then sent to the measurement facility for a lung counting examination. The initial result was $22 \mathrm{~Bq}$ of americium-241 after a shower and change of clothes. Urine and faeces sampling was then prescribed.

The next day, the lung counting was renewed. The activity remained unchanged $(21 \mathrm{~Bq})$ but a much higher level of activity on the lower two detectors was observed. A pulmonary counting was carried out by placing a lead plate at the epigastric level. The result was lower than the detection limit but by positioning the detectors on the stomach, the same initial activity was once again observed. During the whole time period when bioassay samples were collected, Mr. TP was kept outside any zone where there might be a possible risk of contamination.

The lung measurement was done once again 3 days later (following the weekend) and at this time the result was lower than the detection limit (DL $=$ $14 \mathrm{~Bq})$.

On the 5th day, the Mr. TP received an intravenous injection of half an ampulla of Ca-DTPA (500 mg). 


\subsection{Results of the post-incident surveillance}

See Table I.

TABLE I

Results of radiotoxicologic analysis for the first case.

Résultats des examens radio toxicologiques pratiqués dans le premier cas.

\begin{tabular}{cccc}
\hline Day & Examination & Alpha activity & Uncertainty \\
\hline 1 & Nasal mucus smear & $3.2 \mathrm{~Bq}$ & \\
\hline Handkerchief & Lung monitoring & ${ }^{241} \mathrm{Am}$ activity & Uncertainty \\
\hline 1 & pulmonary & $22 \mathrm{~Bq}$ & $9 \mathrm{~Bq}$ \\
2 & Pulmonary with lead screen & $<14 \mathrm{~Bq}$ & \\
2 & basi thoracic & $21 \mathrm{~Bq}$ & \\
5 & pulmonary & $<14 \mathrm{~Bq}$ & \\
5 & basi thoracic & $86 \mathrm{~Bq}$ & \\
\hline
\end{tabular}

\begin{tabular}{|c|c|c|c|c|c|c|}
\hline \multirow[b]{3}{*}{ Day } & \multicolumn{6}{|c|}{ URINE SAMPLES } \\
\hline & \multicolumn{2}{|c|}{${ }^{241} \mathrm{Am}$} & \multicolumn{2}{|c|}{${ }^{238} \mathrm{Pu}$} & \multicolumn{2}{|c|}{${ }^{239-240} \mathrm{Pu}$} \\
\hline & Activity in $\mathrm{Bq} / \mathrm{d}$ & $\begin{array}{c}\text { Uncertainty } \\
\text { in } B q / d\end{array}$ & $\begin{array}{c}\text { Activity in } \\
\mathrm{Bq} / \mathrm{d}\end{array}$ & $\begin{array}{c}\text { Uncertainty } \\
\text { in } B q / d\end{array}$ & $\begin{array}{c}\text { Activity in } \\
\mathrm{Bq} / \mathrm{d}\end{array}$ & $\begin{array}{c}\text { Uncertainty } \\
\text { in } B q / d\end{array}$ \\
\hline $1 *$ & $2.5 \times 10^{-3}$ & $4 \times 10^{-4}$ & $0.6 \times 10^{-3}$ & $2 \times 10^{-4}$ & $0.7 \times 10^{-3}$ & $2 \times 10^{-4}$ \\
\hline 4 & $5.2 \times 10^{-3}$ & $6 \times 10^{-4}$ & $2.8 \times 10^{-3}$ & $5 \times 10^{-4}$ & $2.7 \times 10^{-3}$ & $5 \times 10^{-4}$ \\
\hline 11 & $2.3 \times 10^{-3}$ & $4 \times 10^{-4}$ & $1.2 \times 10^{-3}$ & $3 \times 10^{-4}$ & $1.2 \times 10^{-3}$ & $3 \times 10^{-4}$ \\
\hline 18 & $4.0 \times 10^{-4}$ & $9 \times 10^{-5}$ & $2.0 \times 10^{-4}$ & $7 \times 10^{-4}$ & $2.0 \times 10^{-4}$ & $7 \times 10^{-5}$ \\
\hline 34 & $<3.0 \times 10^{-4}$ & & $<2.0 \times 10^{-4}$ & & $<2.0 \times 10^{-4}$ & \\
\hline 40 & $<2.0 \times 10^{-4}$ & & $<1.0 \times 10^{-4}$ & & $<1.0 \times 10^{-4}$ & \\
\hline 53 & $<2.0 \times 10^{-4}$ & & $<1.0 \times 10^{-4}$ & & $<1.0 \times 10^{-4}$ & \\
\hline \multicolumn{7}{|c|}{ Urine of 16 hours. } \\
\hline & \multicolumn{6}{|c|}{ FAECES } \\
\hline & \multicolumn{2}{|c|}{${ }^{241} \mathrm{Am}$} & \multicolumn{2}{|c|}{${ }^{238} \mathrm{Pu}$} & \multicolumn{2}{|c|}{${ }^{239-240} \mathrm{Pu}$} \\
\hline Day & $\begin{array}{c}\text { Activity in } \\
\mathrm{Bq} / \mathrm{d}\end{array}$ & $\begin{array}{l}\text { Uncertainty } \\
\text { in } B q / d\end{array}$ & $\begin{array}{c}\text { Activity in } \\
\mathrm{Bq} / \mathrm{d}\end{array}$ & $\begin{array}{l}\text { Uncertainty } \\
\text { in } B q / d\end{array}$ & $\begin{array}{c}\text { Activity in } \\
\mathrm{Bq} / \mathrm{d}\end{array}$ & $\begin{array}{l}\text { Uncertainty } \\
\text { in } B q / d\end{array}$ \\
\hline 1 & $3.34 \times 10^{-2}$ & $2 \times 10^{-3}$ & $1.79 \times 10^{-2}$ & $2 \times 10^{-4}$ & $1.23 \times 10^{-2}$ & $1.4 \times 10^{-3}$ \\
\hline 2 & $3.34 \times 10^{-2}$ & $2 \times 10^{-3}$ & $1.79 \times 10^{-2}$ & $2 \times 10^{-4}$ & $1.23 \times 10^{-2}$ & $1.4 \times 10^{-3}$ \\
\hline 11 & $1.6 \times 10^{-3}$ & $5 \times 10^{-4}$ & $1.0 \times 10^{-3}$ & $4 \times 10^{-4}$ & $7.0 \times 10^{-4}$ & $2.4 \times 10^{-4}$ \\
\hline $18 *$ & $<9.0 \times 10^{-4}$ & & $<6.0 \times 10^{-4}$ & & $<3.0 \times 10^{-4}$ & \\
\hline 34 & $<7.0 \times 10^{-4}$ & & $<3.0 \times 10^{-4}$ & & $<2.0 \times 10^{-4}$ & \\
\hline 40 & $<7.0 \times 10^{-4}$ & & $<7.0 \times 10^{-4}$ & & $<6.0 \times 10^{-4}$ & \\
\hline
\end{tabular}




\subsection{Interpretation}

\subsubsection{The exposure conditions}

The original exposure product is MOX (mixed oxide uranium / plutonium). The ICRP model assumed to correspond to this chemical form for lack of more specific information is the absorption type $\mathrm{S}$ (Slow) of the human respiratory tract model (ICRP, 1994), which corresponds to a long period of clearance from the lung into the blood. It should be pointed out that it was an old product that had been stored for several years as anyone could easily observe from the deterioration of the vinyl envelope around the pot.

The isotopic composition of the alpha emitting transuranic elements provided by the responsible for production was: ${ }^{241} \mathrm{Am}(30 \%),{ }^{238} \mathrm{Pu}(50 \%),{ }^{239} \mathrm{Pu}(10 \%)$ and ${ }^{240} \mathrm{Pu}(10 \%)$, which corresponds approximately to the composition found in the excreta.

The atmospheric rise of activity concentration (27 DAC.h), the absence of respiratory protective equipment of the operator, the existence of activity measured on the nasal mucus sample as well as in the initial lung measurement, point together to an inhalation entry.

Furthermore, the slight body contamination on the surface of healthy skin, the rapid local decontamination and the exposure to an aerosol form, all rule out the hypothesis of a percutaneous transfer.

\subsubsection{Evolution of the results of the lung monitoring measurements and comparison with the results of the first fecal sample analyses}

The rapid drop in measured activity at the pulmonary level within 5 days does not correspond to the pulmonary retention predicted by the ICRP model for a type S compound (default for plutonium oxide). Nor does it even correspond to a type $\mathbf{M}$ (default for americium) which predicts practically a plateau of lung retention lasting up to 100 days for the type $\mathrm{M}$ (and almost to $1000 \mathrm{~d}$ for the type $\mathrm{S}$ ) (see Tab. I).

The localized measurement at the level of each detector enabled us to observe an apparent migration of the activity from the thorax towards the basi-thoracic and epigastric area from the first to the second day and then the "disappearance" of the activity on the 5th day. This observation was further complemented by measurements carried out at the abdominal level resulting in $21 \mathrm{~Bq}$ on the second day and $86 \mathrm{~Bq}$ on the 5 th day. However these measurements were interpreted using the lung calibration, which is not adapted to a measurement in another geometry. 
Three hypotheses were initially suggested to explain these measurements:

- an external residual contamination, highly unlikely owing to the absence of a detectable initial body contamination (SPR examination) and which does not explain the apparent migration of the activity between the first (D1) and second (D2) days;

- a quick, systemic transfer from the alveolar-interstitial region. This hypothesis may explain the disappearance of the activity at the pulmonary level but does account for the activity measured at the abdominal level;

- a digestive transit that was either direct or linked to the mechanical clearance from the bronchial region (mucociliary mechanism). This hypothesis is reinforced by the measurement of an activity at the abdominal level as well as by the absence of activity at the thoracic level at the onset of the second day when a lead protection is placed on the abdomen.

Faeces samples taken during the first 48 hours have a total alpha activity of $127.2 \mathrm{mBq}$, including $66 \mathrm{mBq}$ of americium. It is interesting to compare these values with those of the lung monitoring from the first and second days (22 and $21 \mathrm{~Bq}$ of americium, respectively). The discrepancy between the measured values at the thoracic and then epigastric levels and the activity measured in the faeces samples supposedly within the first 48 hours put the hypothesis of a direct digestive transit into doubt. Nevertheless, it should be observed that the faeces sampling undoubtedly was not representative of the first 48 hours of transit. Indeed, the weight of the faeces ashes in the sample $(2.6 \mathrm{~g})$ is less than half of that usually measured. Furthermore, this type of examination is subject to large physiological fluctuations usually rendering their interpretation rather delicate. This is why the results of the faeces analyses of the first days following an incident should be used with care in the estimation of the dose.

\subsubsection{Interpretation of the faecal and urinary radiotoxicological results after the incident of $\mathrm{PuO}_{2}$ contamination under the hypothesis of inhalation with absorption type $S$}

The position of the urinary and faecal excretion points related to the corresponding curves of the ICRP model for plutonium oxide type $S$ with default parameters (ICRP, 1997) enables us to make a certain number of observations:

- the urinary and faecal excretions at the 11th and 18th days are of the same order of magnitude ( $c f$. Tab. I). These results are in discrepancy with the model assumed in which the ratios of faecal excretion / urinary excretion are of the order of $10^{5}$ (initial phase) to $10^{4}$ (after the 10th day) (Fig. 1). Even by taking into account an efficiency factor of the Ca-DTPA (generally ranging between 10 and 100 as reported by Grappin et al., 2007) administrated on D1 and D5 on the $\mathrm{Pu}$ excretion, we are not able to explain these figures. Furthermore, these 


\section{INHALATION ${ }^{238} \mathrm{Pu}$; type $\mathrm{S}$ compounds}

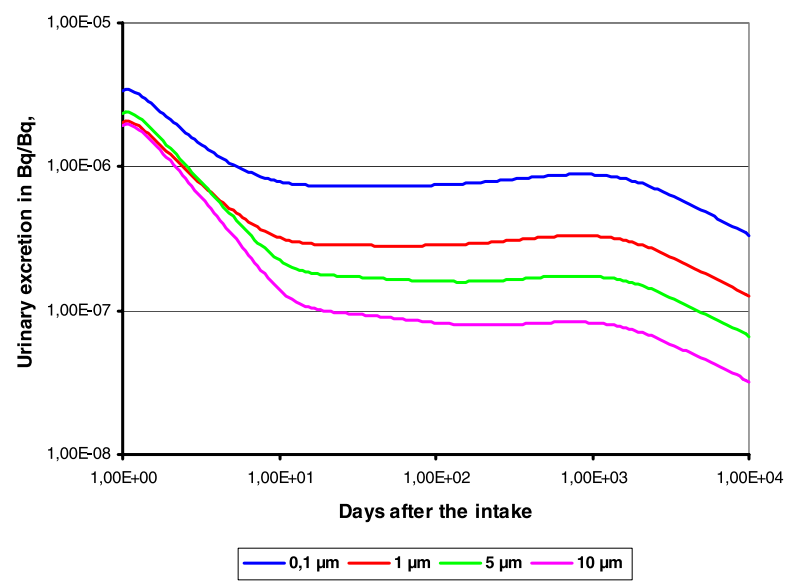

\section{INHALATION ${ }^{238} \mathrm{Pu}$; type $\mathrm{S}$ compounds}

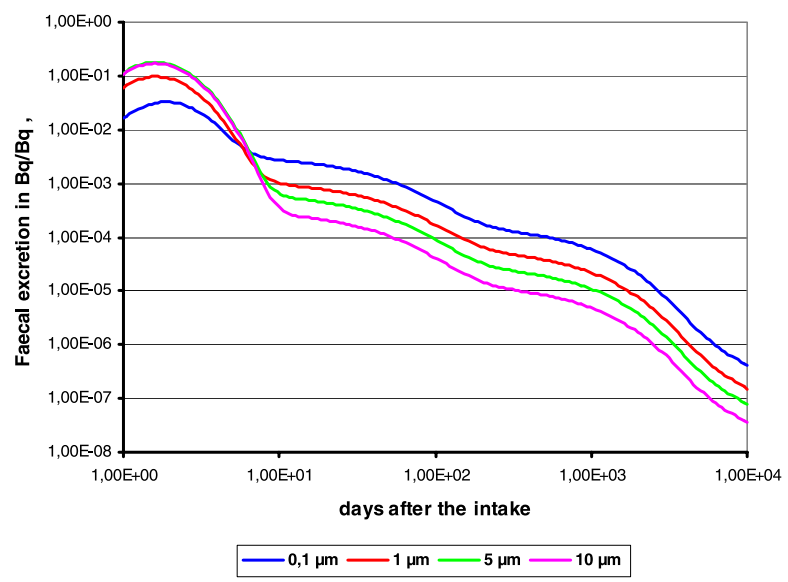

Figure 1 - Urinary and faecal excretion curves in the inhalation model for Pu type S from ICRP(1997). Courbes d'excrétions urinaires et fécales du modèle inhalation type $S$ de la publication 78 de la CIPR (1997).

values appear again in the excretions of the 18th day when the efficiency of the Ca-DTPA is expected to be much less;

- last, the rapid decrease in the results of faecal and especially urinary excretions, up to the disappearance of all activity after 34 days also remains in great discrepancy with the assumed model. 

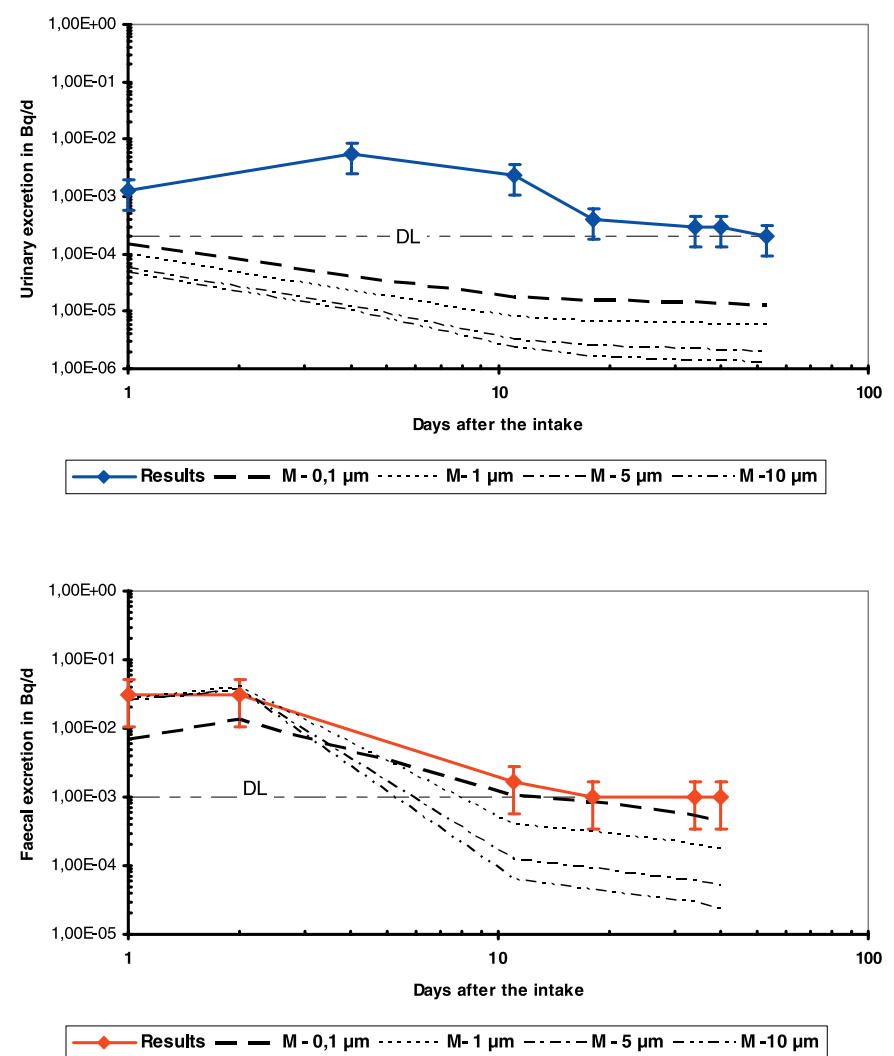

Figure 2 - Urinary and faecal excretion after inhalation of Pu type $M$, with different AMADs, derived from the model of ICRP (1997).

Courbes d'excrétions urinaires et fécales du modèle inhalation type M de la publication 78 de la CIPR (1997).

The age of the product and the hypothesis of a chemical recombination compelled us to envision an absorption behaviour different from type $\mathrm{S}$. We have therefore used the type $\mathrm{M}$ which is the default for chemical forms of Pu/Am other than oxides.

In the graphs of Figure 2, obtained using the IMBA software "Integrated Modules for Bioassays Analysis" (Birchall et al., 1998), we present the results of measurement of urine and faeces in regard of the corresponding curves derived from the ICRP model for the intake through inhalation of type M plutonium aerosols of Activity Median Aerodynamic Diameter (AMAD) ranging between 0.1 and $10 \mu \mathrm{m}$. 
Once again, for the absorption type $\mathrm{M}$, we observe a large discrepancy between the measured results and the predicted values.

The two available models for plutonium inhalation (type $S$ and type $M$ ), whatever the granulometry may be, do not appear to be applicable. The behaviour observed is that of a product that is very transferable with a rapid systemic absorption of an apparent 4-day period which is much more indicative of a type F.

The IMBA ${ }^{\circledR}$ software enabled us to carry out a simulation using a type F model and an AMAD of $0.1 \mu \mathrm{m}$ which provides the best fit of the measured values by the theoretical curve. The curves observed are quite comparable to those of the ICRP publication 78 (1997) for the injection, which is logical since this model describes an instantaneous systemic uptake. In this hypothesis, the Ca-DTPA is assumed to have a small efficiency and the best correlation is obtained by assuming a therapeutic efficiency factor of 1 (Fig. 3).

\subsubsection{Dose assessment}

Due to the absence of an inhalation model consistent with our measurements, we have used the injection model from the ICRP (1997) in order to estimate the uptake. It was calculated by taking the geometric mean based on urine samples of the 4th, 11th, and 18th days as well as on the faeces sample of the 18th day. The first urine samples were not selected given the fact that sampling was not performed in conformance with established procedures (sampling carried out after 16 hours). The result of the faeces analysis of the first 48 hours was not used either; its activity can be explained for the most part by a direct digestive transfer mechanism ( $c f$. Sect. 2.3.2.). The efficiency of the Ca-DTPA on the results of the urinary excretions was neglected, allowing the best adjustment of the theoretical curve to the measured values under our absorption hypotheses.

The systemic uptake is then about $9 \mathrm{~Bq}$. The consistency of the final estimation of the uptake was verified using the latest results of the 34th day which are lower than the detection limit.

\section{Second case}

\subsection{Event circumstances}

An operator, Mr. FL was carrying out an intervention on the active release network of a glovebox where physico-chemical analyses of plutonium were being conducted. The work area is located in a vinyl airlock in which the technicians wear a cotton work uniform and a respiratory protective equipment with no air adduction. 


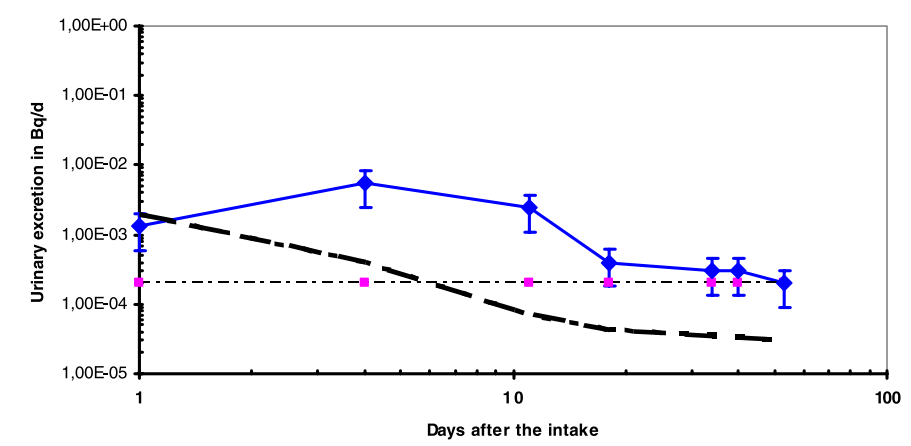

$\multimap-$ Results $--\mathrm{F} \cdot 0,1 \mu \mathrm{m}=-$ - Injection $-\cdot-\cdot-\mathrm{DL}-\cdots-\cdot \cdot$

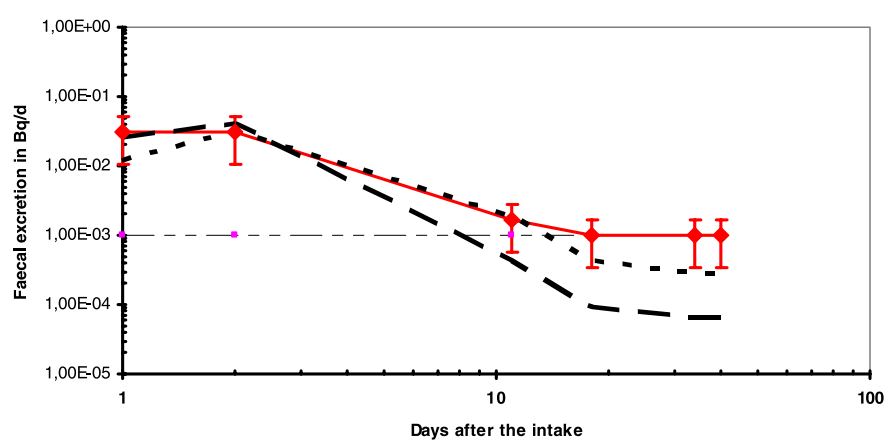

$\longrightarrow-\mathrm{DL} \longrightarrow$ Results - - F-0,1 $\mu \mathrm{m}=-$ - Injection

Figure 3 - Urinary and faecal excretion curves for injection and inhalation of type F AMAD $0.1 \mu \mathrm{m}$ aerosol calculated using the IMBA software.

Courbes d'excrétions urinaires et fécales du modèle injection et du modèle inhalation d'un type F de DAMA 0,1 $\mu$ m déterminés avec le logiciel IMBA.

While unscrewing a joint between the retention pot containing contaminated acid solutions of the glovebox and the discharge channel, the pot fell causing an atmospheric rise of the activity concentration of the order of 1000 DAC.h inside the airlock chamber. After containing the contamination (which possessed the aspect of "brown kitchen salt") on the airlock chamber floor and re-screwing the joint, Mr. FL left the airlock chamber. The radiation protection officer assessed a contamination of his clothing (work uniform and shoes), of the operator's body (about $200 \mathrm{~Bq} / \mathrm{cm}^{2}$ ) and head (about $5 \mathrm{~Bq}$ ) After decontaminating the operator's face and head, the respiratory protective equipment was removed. The activity measured in the sample of nasal mucus was $8 \mathrm{~Bq}$. 
An intravenous injection of half an ampulla of Ca-DTPA (500 mg) was administered.

The lung counting (germanium detector) carried out at the Occupational Medicine Service after a new decontamination was at the level of the detection limit (14 Bq). Urine and faeces analyses were prescribed.

Throughout the entire period of sampling, Mr. FL. was kept in a work area where no risk of contamination existed.

\subsection{Results of the post-incident surveillance}

See Table II.

\subsection{Interpretation}

\subsubsection{Exposure conditions}

Different types of acid solutions have been used in the glovebox for about ten years, so the contaminant may have been nitrate, chloride, oxalate... The ICRP default value for lung absorption corresponding to these chemical forms is the type $\mathrm{M}$.

Despite the fact that the operator was wearing respiratory protective equipment, the intake is a priori through inhalation: the nasal mucus sample was significant and this was confirmed by an analysis of the handkerchief. The contamination observed at the level of the operator's head is consistent with an inhalation at the time of removing the mask even though it had been decontaminated beforehand. No skin lesion was observed.

\subsubsection{Evolution of the results of the analyses}

- The disappearance of the measured activity through lung monitoring within the next 24 hours can be explained, just as in the first case, by the hypothesis of a digestive transit at the time of the initial measurement.

- The results of the first faeces analyses are also compatible with the hypothesis of a digestive transit. The analyses of the faeces samples at more than 10 days later, in other words, after the rapid elimination phase, become lower than those of the urine, something which is not consistent with the predicted values of ICRP publication 78 (1997) for type M.

- By using the type M model, the estimation of intake, based on the urinary results at D30, is in discrepancy with those calculated on D1 and D16. The action of the Ca-DTPA injections on the urinary excretions is assumed to be slight at such a late stage. 


\section{TABLE II}

Results of radiotoxicologic analysis for the second case.

Résultats des examens radio toxicologiques pratiqués dans le deuxième cas.

\begin{tabular}{|c|c|c|c|c|c|c|}
\hline Day & \multicolumn{2}{|c|}{ Examination } & Alp & a activity $(\mathrm{Bq})$ & \multicolumn{2}{|c|}{ Uncertainty } \\
\hline 1 & \multicolumn{2}{|c|}{$\begin{array}{l}\text { Nasal mucus smear } \\
\text { Handkerchief }\end{array}$} & & $\begin{array}{c}8 \\
2.6\end{array}$ & \multicolumn{2}{|c|}{ Undetermined } \\
\hline Day & \multicolumn{2}{|c|}{ Lung monitoring } & \multicolumn{2}{|c|}{${ }^{241}$ Am activity $(\mathrm{Bq})$} & & \\
\hline 1 & \multicolumn{2}{|c|}{ pulmonary } & \multicolumn{2}{|r|}{$14(\mathrm{LD})$} & & \\
\hline 2 & \multicolumn{2}{|c|}{ pulmonary } & \multicolumn{2}{|r|}{$<14$} & & \\
\hline \multirow[t]{3}{*}{43} & \multicolumn{2}{|c|}{ pulmonary } & \multicolumn{2}{|r|}{$<14$} & & \\
\hline & \multicolumn{6}{|c|}{ URINE } \\
\hline & \multicolumn{2}{|c|}{${ }^{241} \mathrm{Am}$} & \multicolumn{2}{|c|}{${ }^{238} \mathrm{Pu}$} & \multicolumn{2}{|c|}{${ }^{239-240} \mathrm{Pu}$} \\
\hline Day & $\begin{array}{l}\text { Activity in } \\
\mathrm{Bq} / \mathrm{d}\end{array}$ & $\begin{array}{l}\text { Uncertainty } \\
\text { in } B q / d\end{array}$ & $\begin{array}{c}\text { Activity in } \\
\text { Bq/d }\end{array}$ & $\begin{array}{l}\text { Uncertainty } \\
\text { in } B q / d\end{array}$ & $\begin{array}{l}\text { Activity in } \\
\text { Bq/d }\end{array}$ & $\begin{array}{l}\text { Uncertainty } \\
\text { in Bq/d }\end{array}$ \\
\hline 1 & $2.1 \times 10^{-2}$ & $2 \times 10^{-2}$ & $2.01 \times 10^{-1}$ & $6 \times 10^{-3}$ & $6.7 \times 10^{-2}$ & $3.4 \times 10^{-3}$ \\
\hline 16 & $3.2 \times 10^{-3}$ & $7 \times 10^{-4}$ & $1.2 \times 10^{-2}$ & $1.7 \times 10^{-3}$ & $3.8 \times 10^{-3}$ & $8.4 \times 10^{-4}$ \\
\hline 30 & $1.0 \times 10^{-3}$ & $3 \times 10^{-4}$ & $4.2 \times 10^{-3}$ & $6 \times 10^{-4}$ & $1.5 \times 10^{-3}$ & $3 \times 10^{-4}$ \\
\hline 44 & $9.0 \times 10^{-4}$ & $4 \times 10^{-4}$ & $3.2 \times 10^{-3}$ & $4 \times 10^{-4}$ & $1.1 \times 10^{-3}$ & $3 \times 10^{-4}$ \\
\hline 101 & $<2.0 \times 10^{-4}$ & & $5.0 \times 10^{-4}$ & $5 \times 10^{-4}$ & $<2.0 \times 10^{-4}$ & \\
\hline \multirow[t]{3}{*}{143} & $<2.0 \times 10^{-4}$ & & $<2.0 \times 10^{-4}$ & & $<2.0 \times 10^{-4}$ & \\
\hline & \multicolumn{6}{|c|}{ FAECES } \\
\hline & \multicolumn{2}{|c|}{${ }^{241} \mathrm{Am}$} & \multicolumn{2}{|c|}{${ }^{238} \mathrm{Pu}$} & \multicolumn{2}{|c|}{${ }^{239-240} \mathrm{Pu}$} \\
\hline Day & $\begin{array}{c}\text { Activity in } \\
\mathrm{Bq} / \mathrm{d}\end{array}$ & $\begin{array}{l}\text { Uncertainty } \\
\text { in Bq/d }\end{array}$ & $\begin{array}{c}\text { Activity in } \\
\text { Bq/d }\end{array}$ & $\begin{array}{l}\text { Uncertainty } \\
\text { in Bq/d }\end{array}$ & $\begin{array}{c}\text { Activity in } \\
\text { Bq/d }\end{array}$ & $\begin{array}{l}\text { Uncertainty } \\
\text { in Bq/d }\end{array}$ \\
\hline 1 & $1.3 \times 10^{-1}$ & $5 \times 10^{-3}$ & 1.63 & $3 \times 10^{-2}$ & $5.58 \times 10^{-1}$ & $2 \times 10^{-2}$ \\
\hline 2 & $1.3 \times 10^{-1}$ & $5 \times 10^{-3}$ & 1.63 & $3 \times 10^{-2}$ & $5.58 \times 10^{-1}$ & $2 \times 10^{-2}$ \\
\hline 16 & $9.0 \times 10^{-4}$ & $2 \times 10^{-4}$ & $2.5 \times 10^{-3}$ & $5 \times 10^{-4}$ & $1.1 \times 10^{-4}$ & $2 \times 10^{-5}$ \\
\hline 17 & $9.0 \times 10^{-4}$ & $2 \times 10^{-4}$ & $2.5 \times 10^{-3}$ & $5 \times 10^{-4}$ & $1.1 \times 10^{-4}$ & $2 \times 10^{-5}$ \\
\hline 30 & $<1.0 \times 10^{-3}$ & & $<1.0 \times 10^{-3}$ & & $<1.0 \times 10^{-3}$ & \\
\hline 31 & $<1.0 \times 10^{-3}$ & & $<1.0 \times 10^{-3}$ & & $<1.0 \times 10^{-3}$ & \\
\hline 101 & $<1.0 \times 10^{-3}$ & & $<1.0 \times 10^{-3}$ & & $<1.0 \times 10^{-3}$ & \\
\hline 210 & $<1.0 \times 10^{-3}$ & & $<1.0 \times 10^{-3}$ & & $<1.0 \times 10^{-3}$ & \\
\hline
\end{tabular}

The results of bioassay analyses become lower than the detection limits for faeces samples after the first month and for urine at the end of the first quarter. The urinary analysis results reveal a "break" around the 30th and the 100th day which does not correspond to the theoretical curves (Fig. 4). 

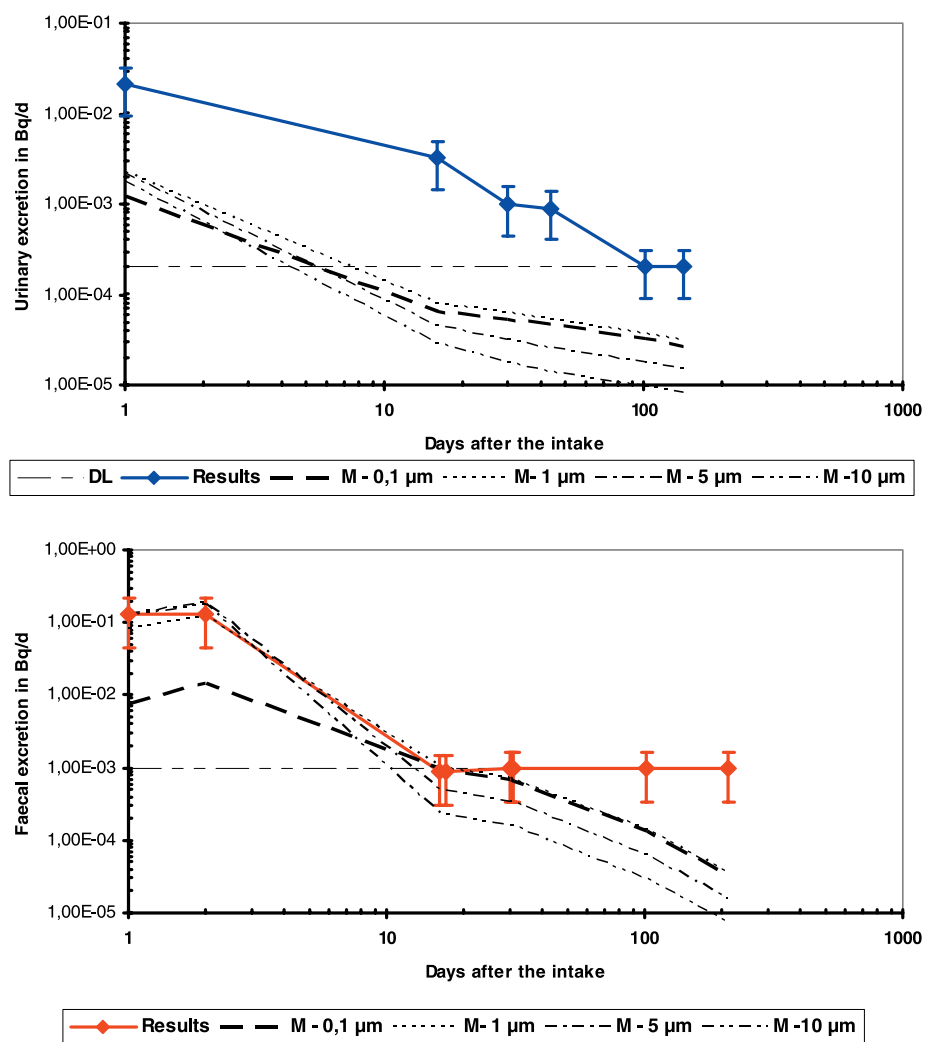

Figure 4 - Urinary and faecal excretion curves for inhalation type $M$ and different AMADs from ICRP (1997).

Courbes d'excrétions urinaires et fécales du modèle inhalation type M de la publication 78 de la CIPR (1997).

\subsubsection{Interpretation of the results}

The observation in the evolution of the urinary and faecal excretion using the IMBA ${ }^{\circledR}$ software, shows the best correlation for an inhalation model with absorption type $\mathrm{F}$ and $\mathrm{AMAD}=0.1 \mu \mathrm{m}$. We may then assume, as in the previous case, a rapid absorption from the respiratory airways, which in practice is comparable to the injection models of the ICRP publication 78 .

Likewise, as in the previous case, the efficiency of the Ca-DTPA on the urinary excretion results was taken as equal to 1 , a value that results in the best adjustment of the measured values with the theoretical curve (Fig. 5). 


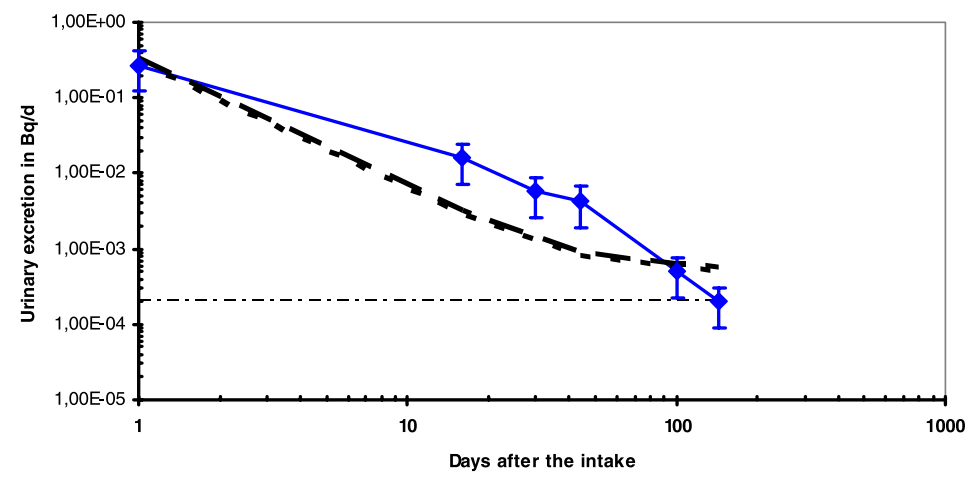

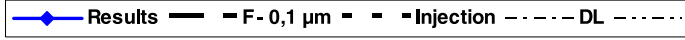

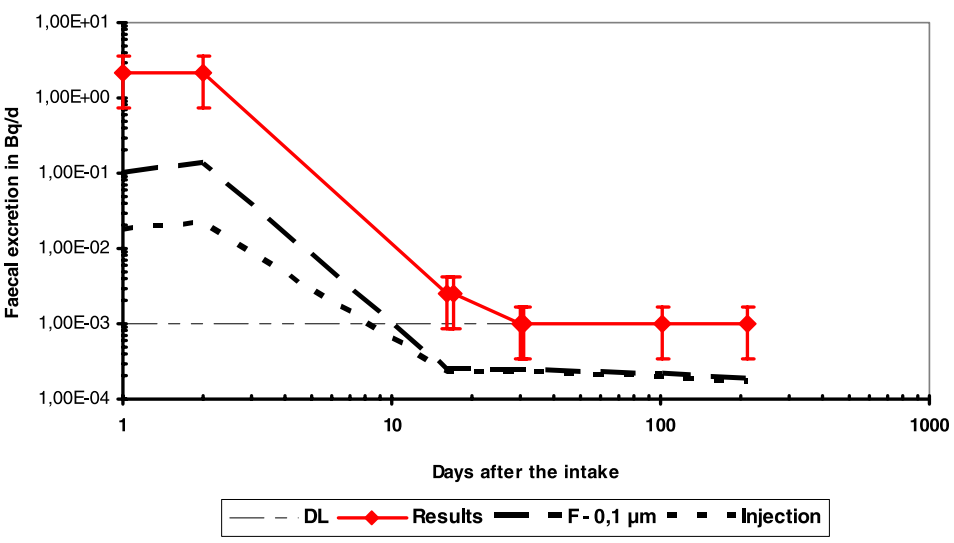

Figure 5 - Urinary and faecal excretion curves assuming injection and according to ICRP (1997). Courbes d'excrétions urinaires et fécales du modèle injection de la publication 78 de la CIPR (1997).

So it was through the application of the injection model of the ICRP, as we have previously seen, that we have analysed this case. The systemic activity was calculated using the geometric mean of the measured fractions based on urine from D1, D16, D30, D44 and D101 (assuming no effect from the Ca-DTPA) as well as from the faeces samples of D16 and D17. The intake result is about $40 \mathrm{~Bq}$.

The coherence of this result was verified with subsequent results (D140 and D210), lower than the detection limit. 


\section{Discussion}

\subsection{Biokinetic mechanisms}

These two cases present a discrepancy between the observed behaviour of the actinides and the excretion functions derived from the ICRP models under standard exposure conditions:

- intake mode: inhalation in both cases,

- chemical form: type $\mathrm{S}$ for the first case and type $\mathrm{M}$ for the second,

- whatever the assumed AMAD. Actually, we do not have any information concerning the granulometry of these old products that are of a heterogeneous composition (pellets, powder crystallized liquid form...). Using an AMAD of $0.1 \mu \mathrm{m}$ yields the best adjustment of the measured points with the inhalation model curve assuming absorption type F. Such kinetics is quite close to the injection model. From the calculation standpoint, this model is satisfactory but it does not enable us to foresee the absorption mechanism based on an inhalation and/or an ingestion.

The similarity between the urinary and faecal excretions in the course of these two very distinct events in time and place, and involving different products (in the first case, an oxide and in the second a nitrate form) is nevertheless remarkable.

The age of the product, confirmed by the high proportion of Americium present in both cases, leads us to the hypothesis of a specific chemical form that might explain this atypical behaviour. A chemical analysis of the product involved in the first event was carried out at the request of the Occupational Medecine Service. This analysis revealed concentrations of chloride in the order of 4000 to $7000 \mathrm{ppm}$ which are most likely linked to the deterioration of the PVC envelope on the pot. The hypothesis of a plutonium chloride form is thus put forward. In the second case, we were unfortunately not able to have the same analysis carried out but we know that it may involve nitrate, chloride, oxalate compounds or even mixtures.

In support of this hypothesis involving plutonium chemical forms with a biokinetic behaviour different from that described in the reference models of the ICRP (absorption types S and M), complementary studies would be necessary not only on the chemical and granulometric levels but also on the anatomopathological level using animal experiments (Métivier et Guillaumont, 2007).

\subsection{Dosimetric estimate}

(a) In the two cases presented here, the dose assessment, using only the analysis results from the first ten days and by applying the reference curve of ICRP (1997) 
with the default assumptions, would have led to the following results:

- In the first case, assuming absorption type $\mathrm{S}$, the estimation of the intake from the urine of D4 and D11 led to a committed effective dose of $300 \mathrm{mSv}$ by applying the corresponding dose coefficient.

It must be pointed out at this stage that the result is in discrepancy with the ambient monitoring of exposure (atmospheric rise of activity concentration at a low level: 27 DAC.h). Furthermore, the rapid disappearance of the activity from the lung is not coherent with this estimation.

The analyses of the first faeces samples (D1 + D2) as well as those of D11 yield a dose lower than $0.1 \mathrm{mSv}$.

This difference with the estimated dose, based on the first urine samples, would imply an efficiency of the Ca-DTPA by a factor of 1000 on the urinary excretion in order to stay consistent with the faeces samples. This factor is far greater than those described in the literature (Grappin et al., 2007).

The activity in the urine at D18, that is 13 days after the last Ca-DTPA injection when its effect should be slight, would lead us to estimate a dose still much greater than that assessed from the faeces (curve in Sect. 2.3.3.).

- In the second case, assuming by default the absorption type $\mathrm{M}$ and using the corresponding dose coefficient, the estimation of the intake from the urine samples of D1 and D16 leads to a dose in the vicinity of $45 \mathrm{mSv}$. Just as in the first case, the faeces analyses as well as those of the late urine excretion are in large discrepancy with this initial estimation.

All of this illustrates the importance of stressing that before confirming a dose assessment, one must first:

1. compare the result of this estimation with the initial conditions of the event,

2. compare the different types of analyses: urine, faeces, lung monitoring,

3. and take into account the results of the late analyses to verify their coherence with the values predicted by the model. Ideally, further analyses will be pursued as long as they are higher than the detection limits.

(b) Furthermore, only the urinary excretion sample measured a long time after the Ca-DTPA treatment allows us to evaluate its efficiency. In the two cases presented, the stability of these evaluations with or without expected effect from the Ca-DTPA (in the initial period after the treatment then after a longer time) suggests a low chelating efficiency, indeed almost inexistent.

(c) The observed excretion curves are evocative of those from the injection model of the ICRP, so they seem consistent with a direct entry into the bloodstream. We therefore used this hypothesis by analogy, for lack of another model to estimate the absorbed systematic activity. This model, considered as qualitatively consistent with the data as indicates the form of the associated 
excretion curves, except for the drop of urinary excretion after the 30th day of the second case, cannot be certified quantitatively to derive a value of intake with full confidence; and above all else it does not correspond to the conditions of exposure.

(d) Observing the inefficiency of the Ca-DTPA leads to the hypothesis of a stable, non-complexed chemical form of Pu inaccessible to the Ca-DTPA. Such chemical form may also present a slight fixation behaviour in the biological tissues (we may recall at this level that in the two cases presented herein, we are dealing with complex chemical forms of which very little is known). Everything may then occurs as if the urinary excretion came out directly from a systemic compartment and not through the recycling or decorporation from a tissue. This could explain, due to the more rapid urinary excretion, the drop observed between the 30th and the 100th day of the second case. If so, the actual intake would probably be lower than that estimated from the injection model and the resulting dose would be consequently lower.

(e) The reliable estimation of a committed effective dose does not appear possible to us due to the absence of a model consistent with the conditions of exposure and with the bioassay data:

- the injection model is used for lack of a better reference model but is not consistent with the conditions of exposure (absence of a wound);

- the hypothesis of an absence of tissue fixation and recycling, resulting in a direct urinary elimination may be considered;

- no corresponding dose coefficient is available from the literature in such nonreference situation.

\section{Conclusion}

In internal exposure situations, the occupational medicine doctor, when making a dosimetric estimation, must take the following precautions:

- compare the results of his estimation with the initial conditions of the event;

- compare the different types of analyses between them: urine, faeces, lung monitoring;

- take into account the results of the late analyses to verify their coherence with the values predicted by the model;

- wait for these late results in order to assess the therapeutic efficiency.

In the two cases presented here, the above precautions have allowed us to reveal the discrepancy with the default ICRP model and to formulate the hypothesis of a specific biokinetic mechanism. The results of the measurements suggest a rapid absorption or a direct urinary excretion with no tissue fixation of a stable $\mathrm{Pu}$ complex inaccessible to the chelation treatment. These hypotheses have been 
examined from the viewpoint of their coherence with the initial conditions, the chemical characteristics of the products and the evolution of the measurements.

The interpretation process should be validated by a referential of good practices. The French working group, MEDOR, Reference Dosimetric Methods (Fritsch et al., 2006) made up of experts, of occupational medicine doctors and biologists, is presently involved in elaborating such a referential. It should be mentioned that this approach will integrate some guidance on variability factors and the associated uncertainties according to the different parameters taken into account.

In closing, it should be stated that we must take into account the psychological impact of an evaluation of a committed effective dose over a period of 50 years and provide the employee with all the information necessary in distinguishing between the concepts of risk and effective dose (Blanchardon et al., 2007)

Acknowledgment. We would like to express here our thanks to Jean Piechowski for his help and precious advices.

\section{REFERENCES}

Birchall A. et al. (1998) The IMBA suite: Integrated Modules for Bioassays Analysis, Radiat. Prot. Dosim. 79, 107-110.

Blanchardon E., Flüry-Hérard A., Paquet F. (2007) Les méthodes et les limites de la dosimétrie après contamination interne, Radioprotection 42, 501-507.

Blanchin N., Desloires S., Grappin L., Guillermin A.-M., Lafon P., Miele A. (2004) Protocoles de prise en charge des incidents d'expositions internes au plutonium dans un service médical d'installation nucléaire de base : Elaboration, mise en place, évaluation, validation de 1996 à 2002, Radioprotection 39, 59-75.

Decree n²003-295 (2003) 01/09/03, Décret relatif à la protection des travailleurs contre les dangers des rayonnements ionisants.

Fritsch P., Raynaud P., Blanchin N., Mièle A. (2006) Incertitudes sur les expositions, les niveaux contamination de et les doses après inhalation d'actinides, Radioprotection 41, 287-308.

Grappin L., Bérard P., Ménétrier F., Carbone L., Courtay C., Castagnet X., Le Goff J.P., Néron M.O., Beau P., Piechowski J. (2007) Exposure to actinides : report on Ca-DTPA injections in CEAAREVA Centres, Radioprotection 42, 163-196.

ICRP Publication 66 (1994) Human respiratory tract model for radiological protection, Ann. ICPR 24(1-3).

ICRP Publication 78 (1997) International commission on radiological protection, Individual monitoring for internal exposure of workers, Ann. ICPR 27(3-4).

ISO Norm 20553 (2006) Surveillance professionnelle des travailleurs exposés à un risque de contamination interne par des matériaux radio-actifs (juillet 2006).

Métivier H., Guillaumont R. (2007) Mieux connaître le devenir biologique des futurs matériaux nucléaires, une nécessité pour maintenir un bon niveau de radioprotection, Radioprotection $\mathbf{4 2}$, 315-335 